\title{
(2) OPEN ACCESS \\ Sex-specific differences in physical health and health services use among Canadian Veterans: a retrospective cohort study using healthcare administrative data
}

\author{
Kate St Cyr $\odot,{ }^{1}$ A B Aiken, ${ }^{2}$ H Cramm $\odot,{ }^{3}$ M Whitehead, ${ }^{4}$ P Kurdyak, ${ }^{4,5}$ A L Mahar ${ }^{4,6}$
}

\begin{abstract}
- Additional supplemental material is published online only. To view, please visit the journal online (http://dx.doi. org/10.1136/bmjmilitary-2021 001915).

${ }^{1}$ Dalla Lana School of Public Health, University of Toronto, Toronto, Ontario, Canada ${ }^{2}$ Dalhousie University, Halifax, Nova Scotia, Canada

${ }^{3}$ School of Rehabilitation

Therapy, Queen's University,

Kingston, Ontario, Canada

${ }^{4}$ ICES, Toronto, Ontario, Canada ${ }^{5}$ Institute for Mental Health Policy Research, Centre for Addiction and Mental Health,

Toronto, Ontario, Canada ${ }^{6}$ Department of Community Health Sciences, University of Manitoba, Winnipeg, Manitoba, Canada
\end{abstract}

Correspondence to Dr A L Mahar, Room 408-727 McDermot Ave, University of Manitoba, Winnipeg MB R3E 3P5, Canada; alyson.mahar@ umanitoba.ca

Received 14 June 2021 Accepted 23 September 2021

Check for updates

(C) Author(s) (or their employer(s)) 2021. Re-use permitted under CC BY-NC. No commercial re-use. See rights and permissions. Published by BMJ.

To cite: St Cyr K, Aiken AB, Cramm H, et al.

BMJ Mil Health Epub ahead of print: [please include Day Month Year]. doi:10.1136/ bmimilitary-2021-001915

\begin{abstract}
Introduction Military occupations have historically been, and continue to be, male dominated. As such, female military Veteran populations tend to be understudied, and comparisons of the physical health status and patterns of health services use between male and female Veterans are limited outside of US samples. This study aimed to compare the physical health and health services use between male and female Veterans residing in Ontario, Canada.
\end{abstract}

Methods A retrospective cohort of 27058 male and 4701 female Veterans residing in Ontario whose military service ended between 1990 and 2019 was identified using routinely collected administrative healthcare data. Logistic and Poisson regression models were used to assess sex-specific differences in the prevalence of select physical health conditions and rates of health services use, after multivariable adjustment for age, region of residence, rurality, neighbourhood median income quintile, length of service in years and number of comorbidities.

Results The risk of rheumatoid arthritis and asthma was higher for female Veterans compared with male Veterans. Female Veterans had a lower risk of myocardial infarction, hypertension and diabetes. No sex-specific differences were noted for chronic obstructive pulmonary disease. Female Veterans were also more likely to access all types of health services than male Veterans. Further, female Veterans accessed primary, specialist and emergency department care at greater rates than male Veterans. No significant differences were found in the sex-specific rates of hospitalisations or home care use.

Conclusions Female Veterans residing in Ontario, Canada have different chronic health risks and engage in health services use more frequently than their male counterparts. These findings have important healthcare policy and programme planning implications, in order to ensure female Veterans have access to appropriate health services.

\section{INTRODUCTION}

Military populations tend to be male dominated. Consequently, female military Veterans are an insufficiently studied and, as a result, potentially medically underserved subpopulation of many ex-serving armed forces communities. In the UK, women make up approximately $11 \%$ of the Veteran population, ${ }^{1}$ while in Canada, women represent $14 \%$ of all Veterans. ${ }^{2}$ In the USA, women represent approximately $10 \%$ of all Veterans, ${ }^{3}$ and

\section{Key messages}

Women serving in the Canadian Armed Forces became eligible to serve in all military roles, including combat, several decades earlier than their UK and US counterparts.

- This study builds on existing research by exploring sex-specific differences in chronic health risk and health services use among Veterans residing in Canada's largest province.

- We found notable sex-specific differences in the risk of chronic conditions and health services use within the first 5 years following military release.

- These findings suggest that female Veterans may benefit from the planning and provision of targeted health services within the first 5 years following their release.

women make up an estimated 11\% of Australian Veterans. ${ }^{4}$ Until recently, sex determined eligibility for a number of defence roles across the military. In Canada, women were historically restricted to roles in medicine, communication and administration. In 1988, women became eligible to serve in any role in the Canadian Armed Forces (CAF), with the exception of submarine service; by 2001, the submarine restriction was lifted and women could serve in all roles. ${ }^{5}$ The provision of equal opportunities to women in CAF occurred notably earlier than in other comparable national military: women were not eligible to serve in all roles in the US and British armies until $2016^{6}$ and $2018,^{7}$ respectively. This may mean that the military experiences and, potentially, health outcomes of contemporary female Veterans in Canada are notably different than those of female Veterans of the US and UK military forces.

Comparisons of physical health outcomes and patterns of health services use between male and female Veterans are scarce outside of US Veteran samples. ${ }^{8}$ Some US studies have demonstrated higher rates of hypertension and diabetes ${ }^{9}$ and cardiovascular concerns, including myocardial infarction (MI) ${ }^{10}$ among male Veterans. Conversely, women appear to have higher rates of asthma ${ }^{11}$ and arthritis, ${ }^{12}$ and are also more likely to seek healthcare than male Veterans. ${ }^{13}$ Given that contemporary female Veterans in Canada are likely to have similar 
occupational exposures and experiences as male Veterans, it is possible that the sex-specific differences in health outcomes documented in US samples are attenuated in Canadian samples. However, there is little evidence about sex-specific differences in Canadian military samples to inform defence and health policy in this area, as much of the existing research in Canada is limited by small numbers of women and other methodological concerns, such as reliance on convenience samples or self-report data.

A clear understanding of whether sex-specific differences in physical health and health services use exist in Veteran populations outside the USA is required to prioritise, target and deliver appropriate health services to female Veterans following their release from the military. Further, research exploring the possibility of sex-specific differences in physical health outcomes and patterns of health services use at the population-level from a public health system could generate valuable information that could be used to inform planning and policy. The objectives of this study are to describe: (1) the prevalence of asthma, chronic obstructive pulmonary disease (COPD), diabetes, hypertension, MI and rheumatoid arthritis (RA); and (2) rates of medical services use (primary care, specialist, emergency department (ED), home care visits and hospitalisations) among Canadian Veterans residing in Ontario using routinely collected administrative healthcare data.

\section{METHODS}

\section{Study design and location}

This study employed a retrospective cohort design of Veterans residing in Ontario, Canada, using routinely collected administrative healthcare data at ICES (formerly the Institute for Clinical Health Sciences), a not-for-profit health services and policy research institute that holds Ontario's health-related administrative data.

\section{Study population}

The study population consisted of Veterans, defined as former members of the CAF or Royal Canadian Mounted Police (RCMP) who provided evidence of their service to the Ministry of Health and Long Term Care (MOHLTC) at the time of enrolment into the Ontario Health Insurance Plan (OHIP). In Canada, health insurance coverage transitions from federal to provincial oversight at the time of departure from the CAF and RCMP; and, in Ontario, the standard 3-month waiting period for provincial health insurance is waived when evidence of CAF or RCMP service is provided. An administrative $\mathrm{CAF} / \mathrm{RCMP}$ code is then linked to the provincial health card, as well as service start and end dates. For this study, the MOHLTC provided an anonymised list of individuals with an administrative CAF/RCMP code. Data anonymisation and linkage to the unique encoded identifier (ICES Key Number (IKN)) were performed according to standard ICES protocol by the ICES Data Acquisition team prior to the research team accessing the data.

\section{Veteran inclusion/exclusion criteria}

Veterans were included in this study if they registered for OHIP between 1 April 1990 and 31 December 2019. As of 1 April 2013, RCMP members no longer receive federal health coverage and so were not captured after this date. The date of OHIP registration is a close approximation of the Veteran's release date from the CAF or RCMP. ${ }^{14}$ We excluded Veterans who had OHIP coverage while still engaged in CAF or RCMP service, as indicated by OHIP billing record dates, or who were younger than 16 years of age at time of enrolment (see online supplemental table 1 for number of participants excluded at each step). Individuals were followed until death, end of OHIP coverage (eg, moved out of province) or until the end of the study period (31 December 2019).

\section{Data sources}

The study linked multiple administrative datasets at the individual level using the IKN. The Registered Persons Database provided age, sex, residential geography and neighbourhood median income data. The OHIP database provided information on eligibility for provincial health services, while the ICES Physician Database was used to identify physician specialty. The Canadian Institute of Health Information Discharge Abstract Database provided information on hospitalisations and the National Ambulatory Care Reporting System provided diagnostic and service information on ED visits.

\section{Statistical analysis \\ Exposure variable}

Sex was the primary exposure variable. This information is collected primarily from the OHIP application form, which requests sex as a dichotomous variable (male/female).

\section{Outcome variables}

This study had two primary outcomes: (1) health outcomes, including risk of asthma, COPD, diabetes, hypertension, MI and RA; and (2) health services use, including primary care physician visits, specialist physician visits, ED visits, hospitalisations and home care visits within the first 5 years of follow-up following release from their service. All health outcomes were identified using standard algorithms ${ }^{15-20}$ and diagnosis dates in diseasespecific derived cohorts held at ICES, and were dichotomised as 5 -year prevalence (yes/no). Primary care visits were defined as visits to doctors with specialties in family medicine or family medicine/emergency medicine, while specialist visits included visits with any other specialist. ED visits included all nonscheduled visits to hospital EDs, while hospitalisations included all inpatient stays, with the exception of those in rehabilitation facilities. All home care visits were included. Each health services use outcome variable was measured as a dichotomous (yes/no) and a count variable.

\section{Covariates}

Covariates for models assessing chronic disease risk were held at their baseline status, and included: age (in years), sex, residential geography, neighbourhood median income quintile, rurality of residence and length of military service (in years). Covariates for models assessing health services use additionally included the presence of the health outcomes identified in the first objective. Neighbourhood median income quintile $(1=$ lowest to $5=$ highest) was determined using census data linked to postal codes. The Rurality Index of Ontario (RIO) assigns municipalities a score (range: 0-100) based on their total population, population density and travel times to healthcare centres. ${ }^{21}$ Using participants' postal codes, we categorised RIO scores as major urban centres (0-9), non-major urban areas (10-30), rural areas (31-50) and rural-remote areas (51+).

Crude prevalence risk ratios (RRs) and 95\% CIs were estimated using logistic regression for asthma, COPD, diabetes, MI and RA; and modified Poisson regression with robust error variance for hypertension. These models were then adjusted for baseline age, length of service, neighbourhood median income quintile and rurality. Crude RRs of (1) primary care visits, (2) 
specialist visits, (3) ED visits, (4) hospitalisations, and (5) home care visits were estimated using logistic regression and modified Poisson regression with robust error variance. Crude rate ratios of each health services visit type, among Veterans with at least one visit, were estimated using Poisson regression. These models were then adjusted for baseline age, length of service, neighbourhood median income quintile, rurality, and presence of asthma, COPD, diabetes, hypertension, MI, and RA. For all analyses, two-sided hypothesis tests were completed, and $\mathrm{p}$ values less than 0.05 were considered statistically significant. Analyses were performed using SAS V.9.4.

\section{Sensitivity analyses}

We restricted the cohort to those who had at least 1 year of follow-up (ie, released from the CAF or RCMP prior to 1 January 2019), and repeated the analytical plan described above.

\section{RESULTS}

\section{Participants}

A total of 36163 Veterans were identified in the administrative data cohort. After removing individuals who did not meet inclusion criteria (see online supplemental table 1), 31759 Veterans were included in the analyses; $14.8 \%(n=4701)$ were female. The average age of all Veterans was 41.80 years $(S D=10.32)$. Veterans had an average of 4.19 years of follow-up $(S D=1.47)$ within the first 5 years following their release from the CAF or RCMP. Table 1 below compares the baseline characteristic distribution between male and female Veterans.

Female Veterans were, on average, slightly younger than male Veterans at the time they transitioned from military service back to civilian life. Notably, significantly fewer female Veterans served for $30+$ years than male Veterans $(7.8 \%$ of female vs $22.6 \%$ of male Veterans).

\section{Risk of chronic disease}

Table 2 compares the crude and adjusted prevalence RRs of asthma, COPD, hypertension, diabetes, MI, and RA between male and female Veterans, within the first 5 years of follow-up following release from the CAF or RCMP.

Statistically significant differences between male and female Veterans were observed for all adjusted prevalence RRs, with the exception of COPD. The adjusted risks of RA and asthma were $135 \%$ and $20 \%$ higher, respectively, among female Veterans compared with male Veterans within the first 5 years of follow-up after transitioning from the CAF or RCMP. However, the adjusted risk of hypertension and diabetes within the first 5 years of follow-up was approximately $35 \%$ less for female Veterans than male Veterans. The risk of MI was $90 \%$ lower for female than male Veterans.

\section{Health services use}

Table 3 displays the proportion of Veterans who had a healthcare encounter at least once within the first 5 years following release from the military, and the RRs for each type of healthcare visit. The majority of Veterans had at least one visit with a primary care provider, and over half of all Veterans had at least one visit with a specialist, regardless of sex. However, female Veterans were more likely than male Veterans to access each type of health service within the first 5 years following release; and were much more likely to be hospitalised (adjusted $\mathrm{RR}=2.52,95 \% \mathrm{CI}=2.30$ to $2.75, \mathrm{p}<0.0001$ ).

Table 4 displays the median number of primary care, specialist, ED, hospitalisations, and home care visits for male
Table 1 Baseline characteristics of male and female Veteran cohorts, standardised differences

\begin{tabular}{|c|c|c|c|c|}
\hline \multirow{2}{*}{$\begin{array}{l}\text { Demographic } \\
\text { characteristic }\end{array}$} & \multicolumn{2}{|l|}{ N Veterans (\%) } & \multirow[b]{2}{*}{ Std diff } & \multirow[b]{2}{*}{ VR } \\
\hline & Male $(n=27058)$ & Female $(n=4701)$ & & \\
\hline $\begin{array}{l}\text { Average age in years } \\
\text { (SD) }\end{array}$ & 42.24 (10.39) & $39.25(9.50)$ & 0.3 & 1.2 \\
\hline \multicolumn{5}{|l|}{ Age } \\
\hline$<30$ years & $4280(15.8)$ & 872 (18.5) & 0.07 & 6.53 \\
\hline 30-39years & $5580(20.6)$ & 1447 (30.8) & 0.23 & 7.49 \\
\hline 40-49years & $9002(33.3)$ & $1653(35.2)$ & 0.04 & 5.91 \\
\hline$\geq 50$ years & $8196(30.3)$ & $729(15.5)$ & 0.36 & 3.57 \\
\hline \multicolumn{5}{|l|}{$\begin{array}{l}\text { Local Health } \\
\text { Integration Network }\end{array}$} \\
\hline Missing & $908(3.4)$ & $176(3.7)$ & 0.02 & 6.4 \\
\hline Erie St Clair & 445 (1.6) & $52(1.1)$ & 0.05 & 3.89 \\
\hline South West & $1095(4.0)$ & $109(2.3)$ & 0.1 & 3.36 \\
\hline $\begin{array}{l}\text { Waterloo } \\
\text { Wellington }\end{array}$ & 415 (1.5) & $48(1.0)$ & 0.05 & 3.85 \\
\hline $\begin{array}{l}\text { Hamilton Niagara } \\
\text { Haldimand Brant }\end{array}$ & $809(3.0)$ & $99(2.1)$ & 0.06 & 4.09 \\
\hline Central West & $203(0.8)$ & $25(0.5)$ & 0.03 & 4.09 \\
\hline Mississauga Halton & $339(1.3)$ & $48(1.0)$ & 0.02 & 4.7 \\
\hline Toronto Central & $252(0.9)$ & $43(0.9)$ & 0 & 5.65 \\
\hline Central & $547(2.0)$ & $75(1.6)$ & 0.03 & 4.56 \\
\hline Central East & $668(2.5)$ & $79(1.7)$ & 0.06 & 3.95 \\
\hline South East & $5369(19.8)$ & $1054(22.4)$ & 0.06 & 6.29 \\
\hline Champlain & $12916(47.7)$ & $2333(49.6)$ & 0.04 & 5.77 \\
\hline $\begin{array}{l}\text { North Simcoe } \\
\text { Muskoka }\end{array}$ & $1999(7.4)$ & $381(8.1)$ & 0.03 & 6.27 \\
\hline North East & $962(3.6)$ & $157(3.3)$ & 0.01 & 5.42 \\
\hline North West & $131(0.5)$ & $22(0.5)$ & 0 & 5.56 \\
\hline \multicolumn{5}{|l|}{$\begin{array}{l}\text { Rurality Index of } \\
\text { Ontario }\end{array}$} \\
\hline $0-9$ & $15243(56.3)$ & 2481 (52.8) & 0.07 & 5.83 \\
\hline $10-30$ & 4875 (18.0) & $834(17.7)$ & 0.01 & 5.69 \\
\hline $31-50$ & $3378(12.5)$ & $603(12.8)$ & 0.01 & 5.89 \\
\hline $51+$ & 3562 (13.2) & $783(16.7)$ & 0.1 & 6.99 \\
\hline \multicolumn{5}{|l|}{ Income quintile } \\
\hline Missing & 991 (3.7) & $192(4.1)$ & 0.02 & 6.39 \\
\hline 1 (lowest) & $2838(10.5)$ & $520(11.1)$ & 0.02 & 6.03 \\
\hline 2 & 4497 (16.6) & $884(18.8)$ & 0.06 & 6.34 \\
\hline 3 & $5638(20.8)$ & $1004(21.4)$ & 0.01 & 5.86 \\
\hline 4 & $6791(25.1)$ & $1123(23.9)$ & 0.03 & 5.57 \\
\hline 5 (highest) & $6303(23.3)$ & $978(20.8)$ & 0.06 & 5.31 \\
\hline \multicolumn{5}{|l|}{ Length of service } \\
\hline$<5$ years & $4873(18.0)$ & $968(20.6)$ & 0.07 & 6.37 \\
\hline 5-9years & 3594 (13.3) & $785(16.7)$ & 0.1 & 6.95 \\
\hline 10-19years & 4219 (15.6) & $1101(23.4)$ & 0.2 & 7.84 \\
\hline 20-29years & 8247 (30.5) & 1481 (31.5) & 0.02 & 5.86 \\
\hline $30+$ years & 6125 (22.6) & $366(7.8)$ & 0.42 & 2.36 \\
\hline \multicolumn{5}{|l|}{ Year of transition } \\
\hline 1990-1995 & 4768 (17.6) & 718 (15.3) & 0.06 & 5.13 \\
\hline $1996-2000$ & 5055 (18.7) & 817 (17.4) & 0.03 & 5.44 \\
\hline 2001-2005 & 4014 (14.8) & $679(14.4)$ & 0.01 & 5.63 \\
\hline 2006-2010 & 4582 (16.9) & 840 (17.9) & 0.02 & 6.01 \\
\hline 2011-2015 & 4378 (16.2) & $851(18.1)$ & 0.05 & 6.29 \\
\hline 2016 or later & 4261 (16.7) & 796 (16.9) & 0.03 & 6.1 \\
\hline
\end{tabular}

Std diff, standardised difference; VR, variance ratio.

and female Veterans (restricted to Veterans who had at least one visit during the follow-up period); and summarises the crude and adjusted relative rate ratios for each type of health service 
Table 2 Crude and adjusted prevalence risk ratios (RRs) of chronic disease, female versus male (reference group) Veterans

\begin{tabular}{|c|c|c|c|c|c|c|}
\hline & \multicolumn{2}{|l|}{$\mathrm{N}$ events (\%) } & \multirow[b]{2}{*}{ Crude RR $(95 \% \mathrm{Cl})$} & \multirow[b]{2}{*}{$P$ value } & \multirow[b]{2}{*}{$\mathrm{aRR}^{*}(95 \% \mathrm{Cl})$} & \multirow[b]{2}{*}{$P$ value } \\
\hline & Male Veterans & Female Veterans & & & & \\
\hline Asthma & $1272(4.7)$ & $305(6.5)$ & 1.41 (1.24 to 1.60$)$ & $<0.0001$ & 1.21 (1.07 to 1.39$)$ & 0.004 \\
\hline COPD & $416(1.5)$ & $61(1.3)$ & 0.84 (0.64 to 1.10$)$ & 0.21 & 1.02 (0.78 to 1.35$)$ & 0.86 \\
\hline Hypertension & $3518(13.0)$ & $299(6.4)$ & $0.45(0.40$ to 0.51$)$ & $<0.0001$ & 0.58 (0.51 to 0.66$)$ & $<0.0001$ \\
\hline Diabetes & $1310(4.8)$ & $116(2.5)$ & $0.50(0.41$ to 0.60$)$ & $<0.0001$ & 0.64 (0.53 to 0.78$)$ & $<0.0001$ \\
\hline $\mathrm{Ml}$ & $134(0.5)$ & \multicolumn{2}{|c|}{ Suppressed due to small cell size } & & $0.10(0.02$ to 0.40$)$ & 0.001 \\
\hline RA & $79(0.3)$ & $27(0.6)$ & 1.97 (1.27 to 3.06$)$ & 0.0024 & 2.35 (1.51 to 3.66$)$ & 0.0002 \\
\hline
\end{tabular}

${ }^{*}$ Adjusted for age, region of residence, rurality, income quintile and length of service.

COPD, chronic obstructive pulmonary disease; MI, myocardial infarction; RA, rheumatoid arthritis.

encounter. Rates of primary care, specialist and ED visits were higher among female Veterans compared with male Veterans; these differences remained after adjusting for age, region of residence, rurality, neighbourhood median income quintile, asthma, COPD, diabetes, hypertension, MI and RA. There were no notable differences in the rates of hospitalisations or home care visits between female and male Veterans.

\section{Sensitivity analyses}

The findings of the sensitivity analyses are presented in online supplemental tables 2-4. After restricting the cohort to those who had at least 1 full year of follow-up $(\mathrm{N}=30548)$, our findings remained unchanged.

\section{DISCUSSION}

Our study found that female Veterans had a greater risk of asthma and RA than male Veterans in the first 5 years following military release, while their risk of diabetes, hypertension and MI was lower. No sex-specific differences were noted in the prevalence of COPD. We also found that most Veterans had at least one encounter with a primary care provider in the first 5 years following their release, regardless of sex, but that female Veterans were more likely than male Veterans to have at least one encounter across each health service type. Additionally, female Veterans accessed primary, specialist and ED care at higher rates than male Veterans within the first 5 years following release from military service. We did not observe notable differences in the rates of hospitalisations or home care.

The sex-specific differences in risk of chronic disease among Veterans residing in Ontario are similar to those reported within US Veteran samples, ${ }^{9-13}$ despite probable differences in the military experiences of female Veterans in Canada and the USA. Similar sex-specific differences in the risks of arthritis, ${ }^{22}$ hypertension, ${ }^{23}$ diabetes and cardiovascular disease ${ }^{24}$ have also been reported in the Canadian general population (see online supplemental table 5). The sex-specific differences in health services use we observed support existing research from studies of US Veterans, as well as the Canadian civilian population. ${ }^{25}$ Unfortunately, there is a dearth of research examining sexspecific differences in the physical health outcomes and health services use within active-duty CAF members or Veterans in the UK or Australia; and there are no other population-level studies comparing sex-specific risks of chronic disease or health services use between male and female Veterans in other Canadian jurisdictions. Given that the occupational exposures and experiences of male and female Veterans in our sample are likely more similar to each other than those of the aforementioned US studies, the similarities in the findings between countries may be more attributable to sex-specific differences in healthcareseeking behaviours, rather than differences in military occupations and experiences. Women are generally believed to engage in healthcare-seeking behaviours more frequently than men. ${ }^{25}$ However, these differences may be attenuated among Veteran populations, as routine contact with health services is common in military populations. This is exemplified in the current study by the high proportion of male and female Veterans who have at least one primary care encounter within the first 5 years of follow-up after release from the CAF $(83.9 \%$ and $86.3 \%$, respectively).

\section{Strengths and limitations}

This is the first study to explore sex-specific differences in the prevalence of select physical health conditions and health services use among Canadian Veterans at the population level. Ontario's size, military presence (eight CAF bases, the Royal Military College, and the RCMP and Department of National Defence headquarters), and the availability of routinely collected administrative healthcare data make it an ideal location to explore sex-specific differences in chronic disease risk

Table 3 Health services use and risk ratios (RRs) of health service encounters within the first 5 years of follow-up, female versus male (reference group) Veterans, by visit type

\begin{tabular}{|c|c|c|c|c|c|c|c|c|}
\hline \multirow[b]{2}{*}{ Visit type } & \multicolumn{2}{|l|}{$\mathrm{N}$ events (\%) } & \multirow[b]{2}{*}{ Crude RR $(95 \% \mathrm{Cl})$} & \multirow[b]{2}{*}{$P$ value } & \multirow[b]{2}{*}{$\mathrm{aRR}^{*}(95 \% \mathrm{Cl})$} & \multirow[b]{2}{*}{$P$ value } & \multirow[b]{2}{*}{ aRRt $(95 \% \mathrm{Cl})$} & \multirow[b]{2}{*}{$P$ value } \\
\hline & Male & Female & & & & & & \\
\hline Primary care & 22708 (83.9) & $4059(86.3)$ & 1.21 (1.11 to 1.23$)$ & $<0.0001$ & 1.34 (1.22 to 1.48$)$ & $<0.0001$ & 1.44 (1.31 to 1.58$)$ & $<0.0001$ \\
\hline Specialist & $15696(58.0)$ & $3088(65.7)$ & 1.39 (1.30 to 1.48$)$ & $<0.0001$ & 1.55 (1.45 to 1.66$)$ & $<0.0001$ & 1.64 (1.53 to 1.75$)$ & $<0.0001$ \\
\hline ED visit & $11081(41.0)$ & $1978(42.1)$ & 1.05 (0.98 to 1.12$)$ & 0.15 & 0.98 (0.92 to 1.05$)$ & 0.55 & 1.01 (0.95 to 1.08 ) & 0.71 \\
\hline Hospitalisation & $2453(9.1)$ & $846(18.0)$ & 2.20 (2.02 to 2.40$)$ & $<0.0001$ & 2.25 (2.06 to 2.45 ) & $<0.0001$ & 2.52 (2.30 to 2.75 ) & $<0.0001$ \\
\hline Home care & $751(2.8)$ & $165(3.5)$ & 1.27 (1.07 to 1.51$)$ & 0.0056 & 1.41 (1.19 to 1.68$)$ & 0.0001 & 1.48 (1.25 to 1.77$)$ & $<0.0001$ \\
\hline
\end{tabular}

*Adjusted for age, region of residence, rurality, income quintile and length of service.

tAdjusted for age, region of residence, rurality, income quintile, length of service and select chronic comorbidities.

$E D$, emergency department; RR, Relative Risk. 
Table 4 Crude and adjusted rate ratios of health service encounters, female versus male (reference group) Veterans, by visit type

\begin{tabular}{|c|c|c|c|c|c|c|c|c|}
\hline \multirow[b]{2}{*}{ Visit type } & \multicolumn{2}{|c|}{ Median \# visits (IQR) } & \multirow{2}{*}{$\begin{array}{l}\text { Crude RR } \\
(95 \% \mathrm{Cl})\end{array}$} & \multirow[b]{2}{*}{$P$ value } & \multirow{2}{*}{$\begin{array}{l}\mathrm{aRR}^{*} \\
(95 \% \mathrm{Cl})\end{array}$} & \multirow[b]{2}{*}{$P$ value } & \multirow{2}{*}{$\begin{array}{l}\text { aRRt } \\
(95 \% \mathrm{Cl})\end{array}$} & \multirow[b]{2}{*}{$P$ value } \\
\hline & Male & Female & & & & & & \\
\hline Primary care & $8(4-15)$ & $12(6-21)$ & 1.43 (1.39 to 1.48$)$ & $<0.0001$ & 1.47 (1.42 to 1.52$)$ & $<0.0001$ & 1.51 (1.46 to 1.56$)$ & $<0.0001$ \\
\hline Specialist & $4(2-9)$ & $6(2-12)$ & 1.45 (1.36 to 1.54 ) & $<0.0001$ & 1.54 (1.45 to 1.64$)$ & $<0.0001$ & 1.56 (1.47 to 1.66$)$ & $<0.0001$ \\
\hline ED & $2(1-3)$ & $2(1-4)$ & 1.17 (1.10 to 1.23 & $<0.0001$ & 1.11 (1.05 to 1.18$)$ & 0.0002 & 1.11 (1.05 to 1.18$)$ & 0.0003 \\
\hline Hospitalisation & $1(1-2)$ & $1(1-2)$ & 1.01 (0.95 to 1.07$)$ & 0.83 & 1.00 (0.92 to 1.08$)$ & 0.96 & 1.00 (0.92 to 1.09$)$ & 0.99 \\
\hline Home care visits & $9(5-26)$ & $8(4-21)$ & 0.81 (0.43 to 1.50$)$ & 0.50 & 0.94 (0.49 to 1.80$)$ & 0.85 & 1.03 (0.54 to 1.96$)$ & 0.94 \\
\hline
\end{tabular}

${ }^{*}$ Adjusted for age, region of residence, rurality, income quintile and length of service.

†Adjusted for age, region of residence, rurality, income quintile, length of service and select chronic comorbidities.

ED, emergency department; IQR, Interquartile range; RR, Rate Ratio.

and health services use patterns of Veterans. Second, our study population includes most of the Veterans residing in Ontario. Veterans Affairs Canada (VAC) estimates that approximately 1050 Veterans release from the CAF and take up residence in Ontario each year ${ }^{14}$; the number, age and sex distribution of Veterans entering our cohort annually are similar. Our cohort has slightly fewer Veterans under 25 years of age and slightly more Veterans 50 years of age and older than expected. This is likely explained by the inclusion of RCMP Veterans who were released between 1 April 1990 and 31 March 2013 in our cohort. Finally, this study adds much-needed international data about the health and health services use of female Veterans. A scoping review conducted in $2018^{8}$ found 108 studies explored some domain of sex, gender, gender norms or gender differences in relation to Veteran health outcomes or health services use; of these studies, only four were conducted outside of the USA $(\mathrm{UK}=2$, Australia $=1$, Canada $=1)$.

There are some limitations to our study. We were unable to separately study CAF and RCMP Veterans as the MOHLTC includes both under a single Veteran status identifier. However, we estimate that approximately $85 \%$ of our cohort are Veterans of the CAF, as fewer than 200 RCMP Veterans take up residence in Ontario per year ${ }^{14}$ and after 31 March 2013, only CAF Veterans were included in the cohort. Second, the administrative healthcare data used in the current study do not capture healthcare-related visits covered under private insurance or VAC supplemental health benefits. As such, we may have underestimated the true rates of health services use among Veterans residing in Ontario; however, we do not anticipate that this potential underestimation would differentially affect women versus men. Third, we did not exclude healthcare visits associated with reproductive care or sex-specific conditions. This may be driving some of the sex-specific differences in health services use observed in this study, and a more granular exploration of these details may further inform healthcare policy and planning. Finally, information about military-specific variables that may lay on the causal pathway between military service and chronic conditions or health services use, such as military occupation and deployment history, was not available.

\section{Policy implications and future research}

The current study provides much-needed information about the physical health and health services needs of female Veterans residing in Ontario, which have not been studied independently of male Veterans to date. This information could be used to inform federal and defence programme planning and resource allocation to ensure that female Veterans are well supported during the transition from military to civilian life. Future longitudinal research examining the stability of these needs over time would further assist with the long-term planning and allocation of healthcare resources at the local and federal levels.

Twitter H Cramm @HeidiCramm, P Kurdyak @KurdyakP and A L Mahar @alyson_ mahar

Contributors $A A, H C, P K$, and AM conceptualised the study. KSC, AA, HC, MW, PK and AM contributed to the study design, data collection, analytical plan and interpretation. MW conducted the statistical analyses. KSC and AM drafted the manuscript. All authors reviewed and approved the manuscript. AM, AA, HC, MW and PK obtained funding. AM is the manuscript's guarantor, and affirms that the manuscript is an honest, accurate and transparent account of the study being reported.

Funding The project was funded by True Patriot Love and the Canadian Institute for Military and Veteran Health Research through the CIMVHR TPL Research Initiative. This study was supported in part by ICES, which is funded by an annual grant from the Ontario Ministry of Health and Long-Term Care (MOHLTC).

Disclaimer The opinions, results, and conclusions reported in this paper are those of the authors and are independent from the funding sources. No endorsement by ICES or the Ontario MOHLTC is intended or should be inferred. Parts of this material are based on data and/or information compiled and provided by $\mathrm{CIHI}$. However, the analyses, conclusions, opinions, and statements expressed in the material are those of the author(s), and not necessarily those of $\mathrm{ClHI}$.

Competing interests The authors received funding from True Patriot Love through a collaboration between True Patriot Love and the Canadian Institute for Military and Veteran Health Research for the submitted work.

\section{Patient consent for publication Not required.}

Ethics approval This study received ethics approval from University of Manitoba's Health Sciences Research Ethics board (protocol number HS22485), and underwent a privacy impact assessment at ICES. Section 45 of the Personal Health Information Protection Act permits prescribed entities such as ICES to collect data and conduct analyses to improve health and healthcare without individual consent.

Provenance and peer review Not commissioned; externally peer reviewed.

Data availability statement Data may be obtained from a third party and are not publicly available. The data set from this study is held securely in coded form at ICES. While data sharing agreements prohibit ICES from making the data set publicly available, access may be granted to those who meet prespecified criteria for confidential access (available at www.ices.on.ca/DAS). The full data set creation plan and underlying analytic code are available from the authors upon request, understanding that the programs may rely upon coding templates or macros that are unique to ICES.

Supplemental material This content has been supplied by the author(s) It has not been vetted by BMJ Publishing Group Limited (BMJ) and may not have been peer-reviewed. Any opinions or recommendations discussed are solely those of the author(s) and are not endorsed by BMJ. BMJ disclaims all liability and responsibility arising from any reliance placed on the content. Where the content includes any translated material, BMJ does not warrant the accuracy and reliability of the translations (including but not limited to local regulations, clinical guidelines, terminology, drug names and drug dosages), and is not responsible for any error and/or omissions arising from translation and adaptation or otherwise.

Open access This is an open access article distributed in accordance with the Creative Commons Attribution Non Commercial (CC BY-NC 4.0) license, which permits others to distribute, remix, adapt, build upon this work non-commercially, and license their derivative works on different terms, provided the original work is 
properly cited, appropriate credit is given, any changes made indicated, and the use is non-commercial. See: http://creativecommons.org/licenses/by-nc/4.0/.

\section{ORCID iDs}

Kate St Cyr http://orcid.org/0000-0002-5858-7612

H Cramm http://orcid.org/0000-0002-8805-063X

\section{REFERENCES}

1 Ministry of Defence. Annual population survey: UK armed forces veterans residing in Great Britain, 2017. Available: https://assets.publishing.service.gov.uk/government/ uploads/system/uploads/attachment_data/file/774937/20190128_-_APS_2017_ Statistical Bulletin - OS.pdf

2 Veterans Affairs Canada. Info brief. fast facts on female and male veterans in Canada 2018. Available: https://www.veterans.gc.ca/pdf/about-us/research-directorate/infobriefs/Female-and-Male-Veterans-in-Canada_Info-Brief.pdf

3 Department of Veterans Affairs. Facts and statistics about women veterans. n.d. Available: https://www.womenshealth.va.gov/WOMENSHEALTH/latestinformation/ facts.asp

4 Australian Institute of Health and Welfare. A profile of Australia's Veterans 2018. Canberra: AlHW, 2018.

5 Government of Canada. Women in the Canadian armed forces. n.d. Available: https:// forces.ca/en/women-in-the-caf/

6 Department of Defense. Women in the Army: History.n.d. Available: https://www. army.mil/women/history/

7 British Armed Forces. All British Armed Forces roles now open to women [press release], 2018. Available: https://www.army.mod.uk/news-and-events/news/2018/10/ women-in-ground-close-combat-roles/

8 Eichler M, Smith-Evans K. Gender in veteran reintegration and transition: a scoping review. J Mil Veteran Fam Health 2018:4:5-19.

9 Vimalananda VG, Miller DR, Christiansen CL, et al. Cardiovascular disease risk factors among women veterans at Va medical facilities. J Gen Intern Med 2013;28 Suppl 2:517-23.

10 Whitehead AM, Maher NH, Goldstein K, et al. Sex differences in veterans' cardiovascular health. J Womens Health 2019;28:1418-27.
11 Bade BC, DeRycke EC, Ramsey C, et al. Sex differences in veterans admitted to the hospital for chronic obstructive pulmonary disease exacerbation. Ann Am Thorac Soc 2019;16:707-14.

12 Weimer MB, Macey TA, Nicolaidis C, et al. Sex differences in the medical care of Va patients with chronic non-cancer pain. Pain Med 2013;14:1839-47.

13 Copeland LA, Finley EP, Vogt D, et al. Gender differences in newly separated veterans' use of healthcare. Am J Manag Care 2020;26:97-104.

14 Mahar AL, Aiken AB, Kurdyak P, et al. Description of a longitudinal cohort to study the health of Canadian veterans living in Ontario. J Mil Veteran Fam Health 2016:2:33-42.

15 Austin PC, Daly PA, Tu JV. A multicenter study of the coding accuracy of hospital discharge administrative data for patients admitted to cardiac care units in Ontario. Am Heart J 2002;144:290-6.

16 Gershon AS, Wang C, Guan J, et al. Identifying patients with physician-diagnosed asthma in health administrative databases. Can Respir J 2009;16:183-8.

17 Gershon AS, Wang C, Guan J, et al. Identifying individuals with physcian diagnosed COPD in health administrative databases. COPD 2009:6:388-94.

18 Hux JE, Ivis F, Flintoft V, et al. Diabetes in Ontario: determination of prevalence and incidence using a validated administrative data algorithm. Diabetes Care 2002;25:512-6.

19 Tu K, Campbell NR, Chen Z-L, et al. Accuracy of administrative databases in identifying patients with hypertension. Open Med 2007;1:e18-26.

20 Widdifield J, Bernatsky S, Paterson JM, et al. Accuracy of Canadian health administrative databases in identifying patients with rheumatoid arthritis: a validation study using the medical records of rheumatologists. Arthritis Care Res 2013;65:1582-91.

21 Kralj B. Measuring Rurality — RIO2008 basic: methodology and results. Toronto, ON: Ontario Medical Association, 2008.

22 Badley EM, Kasman NM. The impact of arthritis on Canadian women. BMC Womens Health 2004;4 Suppl 1:S18-S.

23 Leenen $\mathrm{FHH}$, Dumais J, McInnis NH, et al. Results of the Ontario survey on the prevalence and control of hypertension. CMAJ 2008;178:1441-9.

24 Bushnik T. The health of girls and women, 2016. Available: https://www150.statcan. gc.ca/n1/pub/89-503-x/2015001/article/14324-eng.htm

25 Kazanjian A, Morettin D, Cho R. Health care utilization by Canadian women. BMC Womens Health 2004;4 Suppl 1:S33-S. 